\title{
Up-Regulation of Lamin A/C Expression in Epstein-Barr Virus Immortalized B Cells and Burkitt Lymphoma Cell Lines of Activated B Cell Phenotype
}

Ferenc Banati ${ }^{1}$, Anita Koroknai ${ }^{2}$, Kalman Szenthe ${ }^{1}$, Tamas Tereh ${ }^{2}$, Anita Hidasi ${ }^{2}$, Barbara Bankuti ${ }^{1}$, Krisztina Buzas ${ }^{3}$, Frederic Lemnitzer ${ }^{4}$, Zsolt Ruzsics ${ }^{5}$, Susan Szathmary ${ }^{6}$, Hans Wolf ${ }^{7}$, Daniel Salamon ${ }^{8}$, Janos Minarovits ${ }^{3^{*}}$ and Hans Helmut Niller ${ }^{7}$

${ }^{1} R T$-Europe Nonprofit Research Ltd., Mosonmagyaróvár, Hungary

${ }^{2}$ Microbiological Research Group, National Center for Epidemiology, Hungary

${ }^{3}$ Department of Oral Biology and Experimental Dental Research, University of Szeged, Hungary

${ }^{4}$ Max von Pettenkofer-Institut, Ludwig-Maximilians-Universität München, Germany

${ }^{5}$ University of Freiburg, University Medical Center Freiburg, Institute of Virology, Germany

${ }^{6}$ Galen-Bio Kft., Bartók Béla út 51. I/4, Budapest, H-1114, Hungary

${ }^{7}$ University of Regensburg, Franz-Josef-Strauss Allee 11, Regensburg, D-93053, Germany

${ }^{8}$ Department of Microbiology, Tumor and Cell Biology, Karolinska Institutet, Stockholm, Sweden

\section{Abstract}

Lamin A, B and C, the nuclear intermediate-filament proteins, play a role in epigenetic regulation. Lamin B could be detected in all nucleated cells studied, whereas the lamin $A$ and lamin $C$ isoforms (lamin A/C) encoded by the LMNA gene are co-expressed in most somatic cell types except mature B lymphocytes. Since Epstein-Barr virus (EBV), a human gammaherpesvirus, is associated with tumorigenic processes and is known to alter the epigenotype of its host cells, we studied the expression of the LMNA gene and its epigenetic marks in EBV-carrying human lymphoid cell lines. We observed a high lamin A/C mRNA expression in EBV-immortalized B lymphoblastoid cell lines (LCLs) and in a subset of Burkitt lymphoma (BL) lines characterized by an activated $B$ cell phenotype and a unique latent EBV gene expression pattern (latency III). In these cells the first exon of LMNA was hypomethylated and associated with activating histone marks. In contrast, we observed a low level of lamin A/C mRNA expression in EBV negative BL lines and BL lines with a restricted expression of latent EBV products (latency I). Low LMNA promoter activity was associated with hypermethylation of the LMNA first exon. These data suggest a role for EBV latency products in switching on or upregulating the LMNA promoter (LMNAp) in EBV-infected activated B cells in vitro. Lamin A/C may contribute to the establishment of the activated B cell phenotype. Our data also imply a role of LMNA first exon methylation in the silencing of $L M N A p$.
\end{abstract}

Keywords: Lamin; Epstein-Barr virus latency; Transformation; Epigenetic regulation; Activated B cell

\section{Introduction}

Lamins are intermediate-filament proteins forming a network called nuclear lamina between the inner nuclear membrane and the nucleoplasm that protects the chromatin from physical damage. They play a role in chromatin organization, too, and act as epigenetic regulators affecting the activity of promoters located to the laminassociated domains (LADs) of the genome [1-7]. In addition, lamins may affect the temporal pattern of replication origin firing [8].

There are two types of lamins: A and B. The LMNA gene codes for the widely co-expressed major isoforms, lamin A and lamin C (lamin A/C) generated by alternative splicing [9]. Human B type lamins are expressed from $L M N B 1$ and $L M N B 2$. At least one type B lamin was detected in all nucleated metazoan cells studied so far. In vertebrates lamin $\mathrm{A} / \mathrm{C}$ is expressed predominantly in differentiated somatic cells; only a low level was found in pluripotent mouse embryonic stem cells [10-12]. Murine and human B cells don't express or express only low levels of lamin A/C [13-15].

Epstein-Barr virus (EBV), a human gammaherpesvirus, is regularly associated with human lymphomas of B cell origin and immortalizes human B cells with a high efficiency in vitro [16]. The expression of latent EBV genomes is highly restricted in Burkitt lymphoma (BL) cells that phenotypically resemble resting B cells: only EBNA1, an EBV-encoded nuclear antigen, and a set of non-translated viral RNAs can be detected [17]. The restricted EBV gene expression pattern characteristic of BLs in vivo and BL-derived cell lines that maintain the BL biopsy phenotype in vitro is called latency type I.
A less stringent gene expression pattern (latency type II) was described in nasopharyngeal carcinomas (NPCs): they typically express EBV-encoded latent membrane proteins (LMP1, LMP2A and LMP2B) in addition to the viral latency products detected in BLs. We note, however, that LMP1 is not expressed in a subset of NPCs [18].

The EBV-encoded latent membrane proteins are also expressed in latency type III, characteristic of post-transplant lymphoproliferative disease (PTLDs) developing in immunosuppressed patients and their in vitro counterparts, the in vitro immortalized B lymphoblastoid cell lines (LCLs). In addition to LMPs, however, six nuclear antigens (EBNAs) and three BHRF1 microRNAs are also expressed in latency type III $[17,19,20]$. It is worthy to note, that type III latency is also a characteristic of BL cells that acquired an activated B cell phenotype during in vitro cultivation.

Although it has been well documented that the host cell phenotypedependent expression of viral oncoproteins could switch on or epigenetically silence a series of host cell promoters in EBV-positive lymphomas and carcinoma, the expression of LMNA in B lymphoid

*Corresponding author: Janos M, Department of Oral Biology and Experimental Dental Research, University of Szeged, Hungary, Tel: 36703948279; E-mail: minimicrobi@hotmail.com

Received April 27, 2017; Accepted May 15, 2017; Published May 22, 2017

Citation: Banati F, Koroknai A, Szenthe K, Tereh T, Hidasi A, et al. (2017) UpRegulation of Lamin A/C Expression in Epstein-Barr Virus Immortalized B Cells and Burkitt Lymphoma Cell Lines of Activated B Cell Phenotype. J Microb Biochem Technol 9:087-094. doi: 10.4172/1948-5948.1000349

Copyright: @ 2017 Banati F, et al. This is an open-access article distributed under the terms of the Creative Commons Attribution License, which permits unrestricted use, distribution, and reproduction in any medium, provided the original author and source are credited. 
Citation: Banati F, Koroknai A, Szenthe K, Tereh T, Hidasi A, et al. (2017) Up-Regulation of Lamin A/C Expression in Epstein-Barr Virus Immortalized B Cells and Burkitt Lymphoma Cell Lines of Activated B Cell Phenotype. J Microb Biochem Technol 9:087-094. doi: 10.4172/19485948.1000349

cells carrying latent EBV genomes has not been studied systematically $[21,22]$. The available data on B cell lines and NPCs are based on microarray experiments performed under variable experimental conditions $[23,24]$.

Here we analyzed the expression of LMNA mRNA in wellcharacterized B lymphoid cell lines carrying latent EBV genomes. Unexpectedly, we observed an elevated LMNA transcription in LCLs and the majority of group III BL lines characterized by an activated B cell phenotype, but not in latency type I or EBV-negative B cells. The 5' LMNA promoter flanking sequences were hypomethylated in most of the cell lines analyzed and their methylation pattern did not correlate with promoter activity. We observed, however, that the first LMNA exon that partly overlapped with a CpG island was highly methylated, with one exception, at silent LMNA promoters, suggesting a role for first exon methylation in the regulation of LMNAp. Active LMNA promoters were enriched in euchromatic histone marks.

\section{Materials and Methods}

\section{Cell lines and culture conditions}

Well-characterized EBV-negative B lymphoma and BL lines, EBV-positive BL cell lines or clones, EBV-immortalized LCLs and carcinoma cell lines were maintained as described earlier [25,26] (Table 1). Cell lines were regularly tested for latency type-associated mRNA transcripts of LMP1 (EBV latency type II and III) and EBNA2 (EBV latency type III) using reverse transcription and real-time PCR to verify their originally described characteristics.

\section{Real-time quantitative PCR}

Total RNA was isolated from the cells using TRI Reagent (Sigma), followed by DNase I treatment of $1 \mu \mathrm{g}$ RNA and reverse transcription with Transcriptor High Fidelity cDNA Synthesis Kit (Roche) using lamin A/C (LMN-RT) and GAPDH-specific (GAPDH-RT) oligonucleotides. The relative levels of transcripts initiated at LMNAP (the LMNA promoter) were determined with real-time polymerase chain reaction (LightCycler 480; Roche) using LightCycler FastStart DNA Master SYBR Green I Kit (Roche) with primers complementary to lamin A/C and GAPDH coding sequences (Supplementary Table $\mathrm{S} 1$ ). The relative expression of lamin A/C mRNA was normalized to the level of GAPDH mRNA. To present reliable expression data we normalized Lamin A/C mRNA level to $18 \mathrm{~S}$ rRNA and $\beta$-actin mRNA amounts (not presented) as well, giving nearly identical results. Primers are designed to amplify cDNA from mRNA only by harboring splicing sites or surrounding large introns.

\section{CpG island search}

We used the Methyl Primer Express v1.0 Software (Applied Biosystems), with the following parameters: minimum length of island, 400; maximum length of island, 2000; C+Gs/total bases $>60 \%$; $\mathrm{CpG}$ observed/CpG expected $>0.65$.

\section{Sequencing of control and sodium bisulfite-modified DNA samples}

Control DNA sequences of the 5' regulatory region and part of the first exon of the LMNA gene were determined using the primers listed. GenBank accession numbers: BJAB: KF791133; BL41: KF791131; DG75: KF791134; Jijoye p79: KF791135; Rael: KF791136; LCL-721: KF791137; CB-M1-Ral-STO: KF791138; Raji: KF791139; Mutu-BL-ICl-216: KF791142; Mutu-BL-III-Cl-99: KF791143; C666-1: KF791144.

For bisulfite sequencing, we used the method of Frommer et al. [36] adapted for an automated DNA sequencer using primers listed [33,37]. The degree of cytosine methylation was estimated as described earlier [25,37].

\section{Chromatin immunoprecipitation (ChIP)}

ChIP was performed according to Weinmann and Farnham [38] with some adaptations as described earlier using specific antibodies against Acetylated Histone 3 (Upstate, 06-599), Acetylated Histone 4 (Upstate, 06-598) and dimethylated lysine 4 of Histone 3 (Upstate, 07-030) or normal rabbit IgG (Santa-Cruz Biotechnology, sc-2027) $[25,35,39]$. Obtained DNA fractions were analyzed using primers specific for the 5 ' regulatory region and exon 1 of LMNA.

\section{Trichostatin A and 5-azacytidine treatment}

The histone deacetylase-inhibitor trichostatin A (TSA; Sigma) was added to $5 \times 10^{6}$ DG75 or BJAB cells in $150 \mathrm{nM}$ end concentration. After treatment, LMNA transcripts were quantified as described above. The demethylating agent 5-azactidine (AzaC; Sigma) was added to $5 \times$ $10^{6}$ DG75, BJAB or Rael cells in 10 or $4 \mu \mathrm{M}$ end concentration for 0,1 , 2 or 3 days, followed by lamin A/C mRNA analysis. The efficiency of $\mathrm{AzaC}$ treatment was monitored by assessing the level of the viral LMP1 mRNA that is known to be upregulated by AzaC in Rael cells $[30,35,40]$.

\begin{tabular}{|c|c|c|c|}
\hline Designation & Origin/EBV latency type & Notes & References \\
\hline BJAB & B cell lymphoma/EBV-negative & & {$[25,27]$} \\
\hline DG75 & Sporadic BL¹/EBV-negative & & {$[25]$} \\
\hline BL41 & Sporadic BL/EBV-negative & & [25] \\
\hline Rael & Endemic BL/latency type I & & [28] \\
\hline Mutu-BL-I-Cl-216 & Endemic BL/latency type I & Subclone of the BL line Mutu & [29] \\
\hline BL41-E95B & In vitro EBV-converted BL/latency type III & $\begin{array}{l}\text { BL41 cells were converted with the B95-8 EBV } \\
\text { strain }\end{array}$ & [30] \\
\hline Mutu-BL-III-Cl-99 & Endemic BL/latency type III & Subclone of the BL line Mutu & [29] \\
\hline Raji & Endemic BL/latency type III & $\begin{array}{c}\text { Deletetion/truncation of EBNA3C, LMP2A, BALF1, } \\
\text { BARF1, BZLF2, BALF2 and BERF5 }\end{array}$ & {$[31]$} \\
\hline Jijoye p79 & Endemic BL/latency type III & Moderate expression of EBNA2 & [25] \\
\hline CB-M1-Ral-STO & $\mathrm{LCL}^{2} /$ latency type III & Immortalized by the Rael EBV strain & [28] \\
\hline LCL-721 & LCL/latency type III & Immortalized by the B95-8 EBV strain & [32] \\
\hline KR4 & LCL/latency type III & & {$[25]$} \\
\hline C666-1 & NPC $3 /$ latency type I & Established from an undifferentiated NPC & [33-35] \\
\hline
\end{tabular}

${ }^{1}$ BL: Burkitt Lymphoma; ${ }^{2}$ LCL: Lymphoblastoid Cell Line; ${ }^{3} \mathrm{NPC}$ : Nasopharyngeal Carcinoma Cell Line

Table 1: Characteristics of the cell lines included in the study. 
Citation: Banati F, Koroknai A, Szenthe K, Tereh T, Hidasi A, et al. (2017) Up-Regulation of Lamin A/C Expression in Epstein-Barr Virus Immortalized B Cells and Burkitt Lymphoma Cell Lines of Activated B Cell Phenotype. J Microb Biochem Technol 9:087-094. doi: 10.4172/19485948.1000349

\section{Statistical analysis}

All variables were tested for normal distribution using $\mathrm{F}$ probe to select the appropriate parametric or non-parametric statistical procedure. As a result, Mann-Whitney U test was used for the statistical evaluation of mRNA expression levels between groups of cell lines. Statistical significance was accepted at a p value of $<0.01$

\section{Results}

\section{Analysis of lamin A/C expression}

The level of LMNA transcripts was high in the LCLs: CB-M1-RalSTO, LCL-721 and KR4 and in C666-1 (an NPC line) and in latency type III BL cell line: Jijoye p79, moderate in latency type III BL cells (Mutu-BL-III-Cl-99 and BL41-E95B) (Figure 1). A low level of LMNA transcripts was detected in EBV latency type I BL cells (Rael, Mutu-BLI-Cl-216), as well as in the latency type III Raji and the EBV-negative $\mathrm{B}$ cell and BL lines BJAB and DG75, BL41. The difference in LMNA mRNA levels between LCLs and other B cells was highly significant $(p<0.001)$. In addition the expression was significantly higher in BLs carrying latency type III EBV genomes compared to other Burkitt lymphoma cells $(\mathrm{p}<0.01)$ (Figure 1$)$.

\section{CpG methylation map of the LMNA promoter}

Control sequencing of the 5' and 3 ' flanking sequences of the LMNA promoter revealed a C/A heterozygosity at position 4774 (-227bp to transcription start site: TSS) in Mutu-BL-I-Cl-216 and Mutu-BL-IIICl-99 and a C-to-A change at position 5282 (+282bp to TSS) in C666-1 cells, compared with the reference sequence NG_008692.1.

Using the Methyl Primer Express Software v1.0 (Applied
Biosystems) we identified a 739 bp long CpG island encompassing the 3 ' end of the regulatory region and the 5 ' end of the first exon of $L M N A$ (CpG island: nucleotides -244 to +495 , grey box (Figure 2).

In order to correlate lamin $\mathrm{A} / \mathrm{C}$ expression with the $\mathrm{CpG}$ methylation pattern of LMNAp, we performed bisulfite genomic sequencing (Figure 2). Independently of $L M N A$ transcription level, the 5 ' regulatory region was hypomethylated with the exception of BL41-E95B, Mutu-BL-IIICl-99 and Raji, where highly or moderately methylated CpGs were detected. The situation was quite different at the 3' flanking sequences of the promoter: we found highly methylated $\mathrm{CpG}$ dinucleotides within the first LMNA exon in cell lines showing a low level of LMNA mRNA expression, except for BJAB that was hypomethylated in this region. In contrast, in LCLs and C666-1 nasopharyngeal carcinoma cells that expressed high levels of LMNA mRNA, exon 1 was either unmethylated or hypomethylated. We noticed that although the 5' regulatory sequences and exon 1 of LMNA were highly methylated in Mutu-BLIII-Cl-99, this clone exhibited a high level of LMNA mRNA (Figure 2).

\section{Analysis of euchromatic histone marks at the LMNA promoter}

We analyzed the euchromatic, activating histone marks at LMNAP using ChIP. Both the 5 ' regulatory region and exon 1 of LMNA were enriched in acetylated Histone 3 (AcH3) in all three LCLs (KR4, CBM1-Ral-STO and LCL-721) expressing lamin A/C. In the lamin A/Cpositive C666-1 cells, AcH3 was detected in high abundance only within the first LMNA exon (Figure 3).

In $\mathrm{BL}$ cells, the level of $\mathrm{AcH} 3$ was highly variable in the 5 ' regulatory sequences of LMNAp: it was hardly detectable in Rael and Mutu-BL-ICl-216 (low promoter activity) and in Mutu-BL-III-Cl-99 (moderate promoter activity) and highly enriched in cell lines both with low

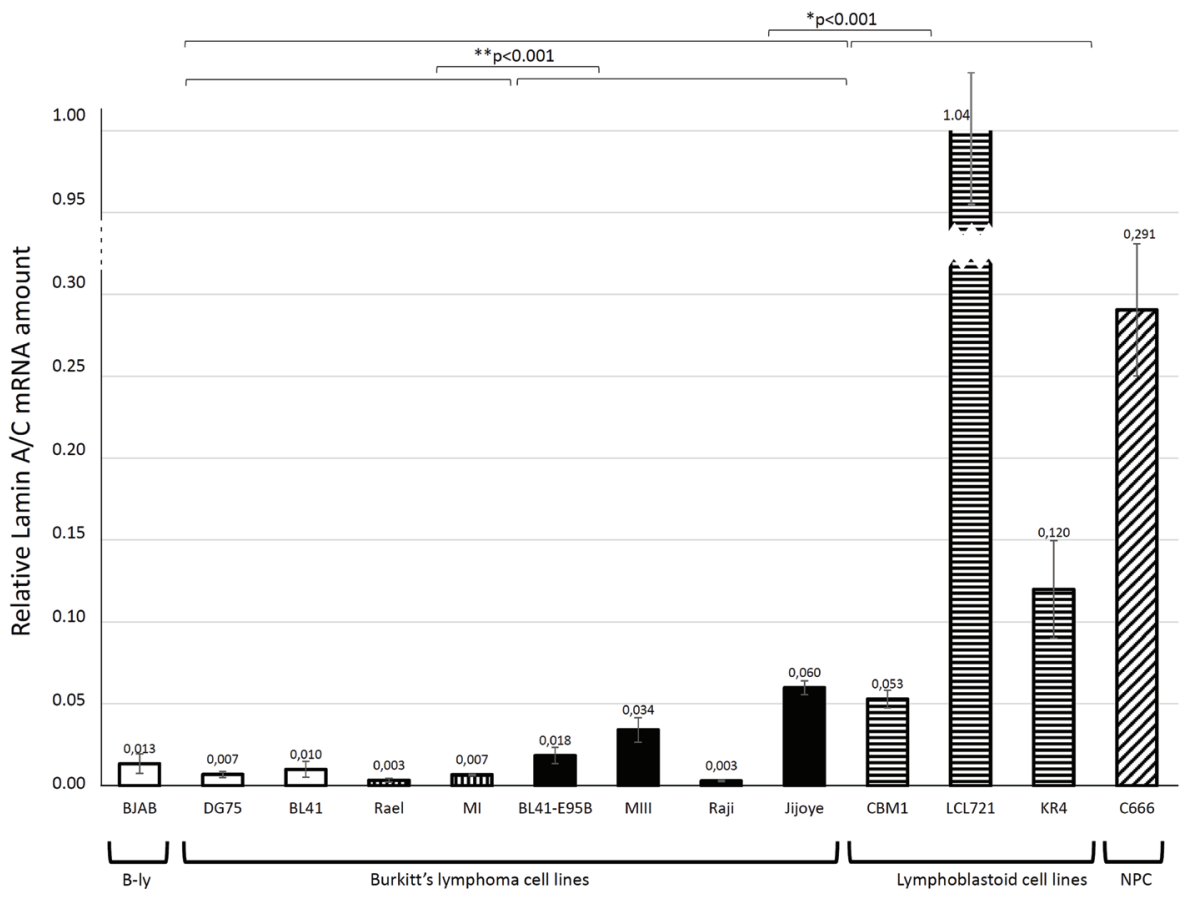

Figure 1. Expression of lamin $A / C$ in $B$ lymphoid and carcinoma cell lines.

In panel A, Relative lamin A/C mRNA expression was quantified by real-time RT-PCR normalized to GAPDH mRNA level. Results are average of three biological replicates. Abbreviations: MI: Mutu-BL-I-Cl-216; MIII: Mutu-BL-III-CI-99; BL41-E: BL41-E95-B; CBM1: CB-M1-Ral-STO; C666: C666-1; B-Iy: B cell Iymphoma; NPC: nasopharyngeal carcinoma cell line. The $p$ value between groups of BL derived cells versus LCLs is indicated above the chart; similarly, the $p$ value between a group of cell lines consisting of EBV-negative BLs and EBV-positive latency type I BLs versus EBV-positive latency type III BLs is also indicated. 
Citation: Banati F, Koroknai A, Szenthe K, Tereh T, Hidasi A, et al. (2017) Up-Regulation of Lamin A/C Expression in Epstein-Barr Virus Immortalized B Cells and Burkitt Lymphoma Cell Lines of Activated B Cell Phenotype. J Microb Biochem Technol 9:087-094. doi: 10.4172/19485948.1000349

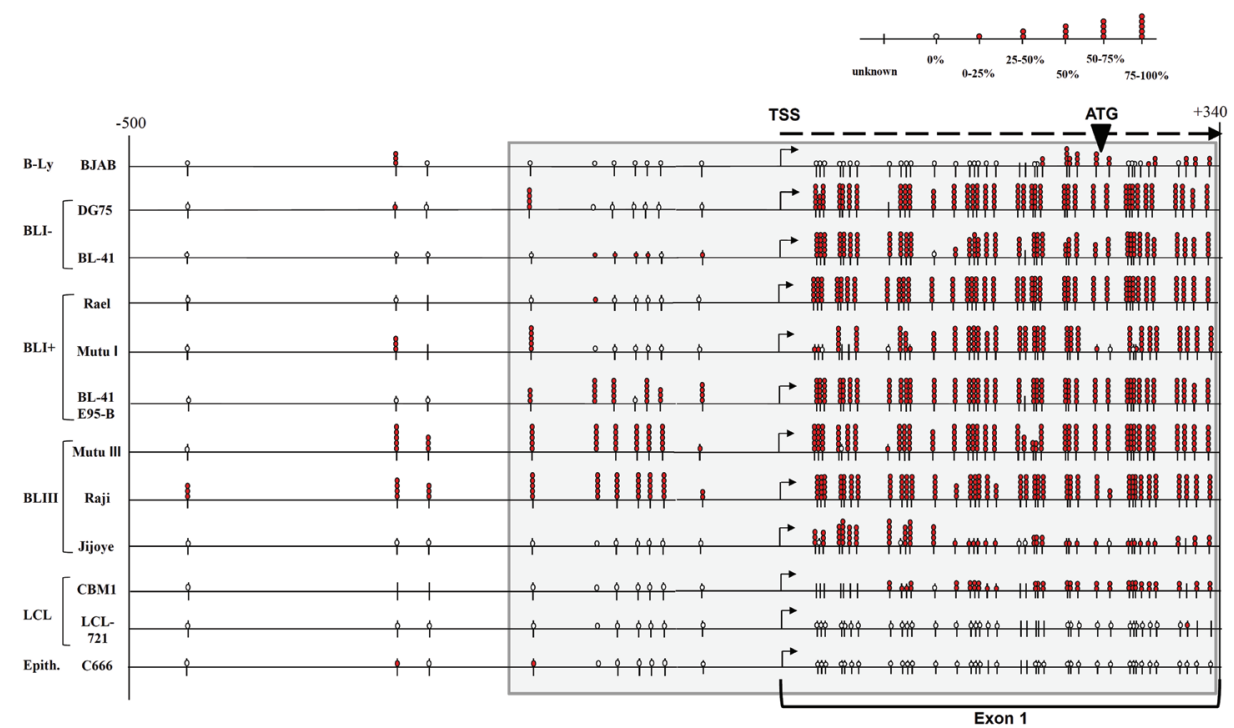

Figure 2: $\mathrm{CpG}$ methylation map of the 5 ' regulatory sequence and exon 1 of LMNA.

The localization of the CpG island in the analyzed region is indicated by a grey box. Symbols: rightward arrow, transcription start site (TSS); Black triangle, (ATG): Start codon; thin vertical lines, positions of CpG dinucleotides. Cytosine methylation levels in cell lines and clones are indicated as follows: stick only, undetected; empty dot, $0 \%$; full dot, $0 \%-25 \%$; two dots, $25 \%-50 \%$; three dots, 50\%-75\%; four dots, $75 \%-100 \%$. Exon 1: the promoter proximal region of the 1 st exon. Abbreviations: B-ly: B cell Iymphoma; BL: EBV-negative Burkitt lymphoma; BLI: EBV-positive Burkitt lymphoma, latency I; BLIII: EBV-positive Burkitt lymphoma, latency III; LCL: Iymphoblastoid cell line; NPC: nasopharyngeal carcinoma cell line; Mutu I: Mutu-BL-I-Cl-216; Mutu III: Mutu-BL-III-CI-99; CBM1: CB-M1-Ral-STO; C666: C666-1 nasopharyngeal carcinoma line.
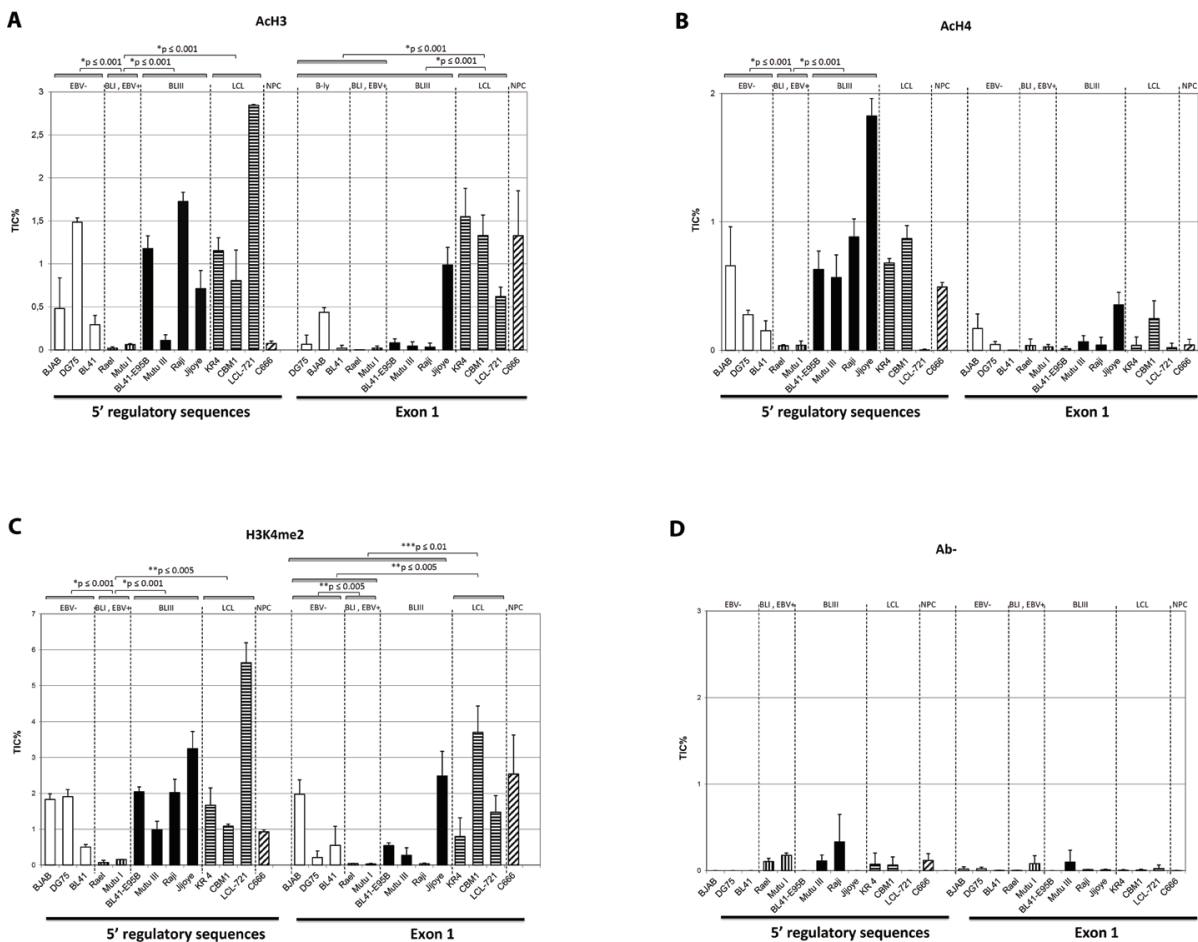

Figure 3: Levels of euchromatic histone modifications at the LMNA promoter.

Chromatin immunoprecipitation (ChIP analysis) of $\mathrm{AcH} 3(\mathrm{~A}), \mathrm{AcH} 4(\mathrm{~B})$ and $\mathrm{H} 3 \mathrm{~K} 4 \mathrm{me} 2(\mathrm{C})$ levels. In D normal rabbit lgG was used. Results are average of three biological replicates expressed as the percentage of input DNA ( $\mathrm{TIC}$, total input chromatin). Antibodies specifically recognizing diacetylated histone $\mathrm{H} 3$ (AcH3), tetraacetylated histone $\mathrm{H} 4(\mathrm{AcH} 4)$ and histone $\mathrm{H} 3$ dimethylated at lysine $4(\mathrm{H} 3 \mathrm{~K} 4 \mathrm{me} 2)$, respectively, were used for ChIP analysis as described earlier [39].

Vertical dashed lines separate groups of cell lines as indicated on the top of the chart. Grey, thick horizontal lines represent groups that were analyzed for statistical significance. The $p$ values between groups analyzed for significance are indicated on the top of the charts. Abbreviations: BL, EBV-negative Burkitt lymphoma; BLI: EBVpositive Burkitt lymphoma, latency I; BLIII: EBV-positive Burkitt lymphoma, latency III; LCL: lymphoblastoid cell line; NPC: nasopharyngeal carcinoma cell line; Mutu I: Mutu-BL-I-Cl-216; Mutu III: Mutu-BL-III-CI-99; CBM1: CB-M1-Ral-STO; C666: C666-1 nasopharyngeal carcinoma line. 
Citation: Banati F, Koroknai A, Szenthe K, Tereh T, Hidasi A, et al. (2017) Up-Regulation of Lamin A/C Expression in Epstein-Barr Virus Immortalized B Cells and Burkitt Lymphoma Cell Lines of Activated B Cell Phenotype. J Microb Biochem Technol 9:087-094. doi: 10.4172/19485948.1000349

(DG75, Raji) or moderate (Jijoye p79) promoter activity. In exon 1, $\mathrm{AcH} 3$ was nearly undetectable in the examined cell lines except BJAB and Jijoye p79.

Acetylated Histone 4 (AcH4) was hardly detectable in the LMNA 5' regulatory region in Rael and Mutu-BL-I-Cl-216, but it was abundant in all latency type III cells independently of promoter activity, with the exception of LCL-721. C666-1 cells were enriched in AcH4 in the $L M N A 5^{\prime}$ regulatory region. Exon 1 of $L M N A$ was poor in $\mathrm{AcH} 4$ in all cell lines except BJAB, Jijoye p79 and CB-M1-Ral-STO.

Histone $\mathrm{H} 3$ dimethylated at lysine 4 (H3K4me2) was hardly detectable at the LMNA 5 ' regulatory region in Rael and Mutu-BL-I$\mathrm{Cl}-216$ but it was moderately or highly enriched in all other cell lines examined. Exon 1 of LMNA showed an elevated H3K4me2 level in all latency type III cell lines with moderate or high LMNA promoter activity, except Mutu-BL-III-Cl-99 (Figure 3).

The abundancy of all three histone modifications on the 5' regulatory sequence was significantly higher in latency type III BLs and LCLs compared to group I BL cell lines.

Immunoprecipitation with control normal rabbit IgG showed no significant enrichment in any cell lines.

\section{Effect of AzaC and TSA treatment on LMNA transcription}

The DNA hypomethylating agent 5-azacytidine did not affect the expression of LMNA in DG75, BJAB and Rael cells although it upregulated the expression of the methylated viral LMP1 gene in Rael cells as observed earlier indicating that the demethylation was effective $[30,35,40]$ (Figure 4).

To test whether increased histone acetylation indeed can activate LMNAp, we treated EBV-negative $\mathrm{B}$ and $\mathrm{BL}$ lines with the histone deacetylase-inhibitor TSA. The LMNA 5' regulatory sequences were unmethylated in both cell lines, but they differed as to the methylation pattern of exon 1 that was methylated in DG75 cells but unmethylated in BJAB cells (Figure 2). TSA induced only a moderate elevation in LMNA gene expression in DG75 cells and a remarkably stronger increase in LMNA promoter activity in BJAB cells.

\section{Discussion}

Type B lamins are widely expressed in metazoan cells $[41,42]$. Although both type A/C and B lamins are present in most murine and human somatic cells, hematopoietic cells express lamin B only $[15,43,44]$. Accordingly, B lymphoid cells (centrocytes and centroblasts)
A

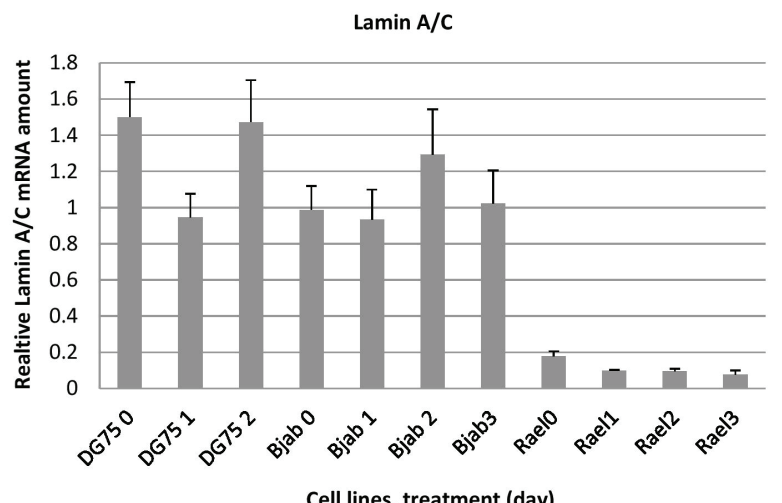

C

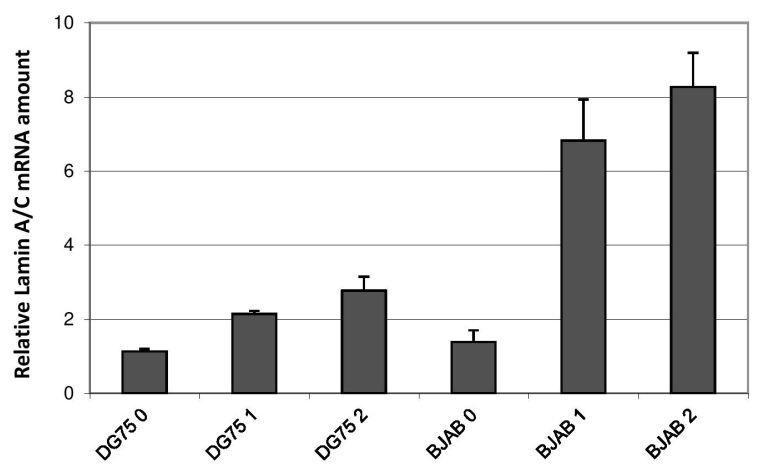

Cell lines, treatment (day)
B

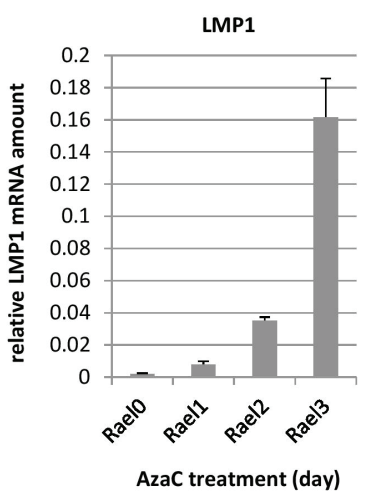

AzaC treatment (day)

Figure 4: Effect of 5-azacytidine and trichostatin A (TSA) treatment on LMNA transcription

A) DG75, BJAB and Rael cells were treated with 10 or $4 \mu \mathrm{M} 5$-azacytidine for $0,1,2$ or 3 days and analyzed for relative lamin A/C mRNA expression. B) Rael cells treated with $4 \mu \mathrm{M}$ 5-azacytidine for $0,1,2$ or 3 days were analyzed for the expression of the methylation-sensitive EBV latency gene LMP1. C) DG75 and BJAB cells were treated with $150 \mathrm{nM}$ TSA for 0,1 or 2 days, respectively and analyzed for relative lamin A/C mRNA expression. Relative lamin A/C mRNA expression was quantified by real-time RT-PCR. Results are average of three biological replicates. 
Citation: Banati F, Koroknai A, Szenthe K, Tereh T, Hidasi A, et al. (2017) Up-Regulation of Lamin A/C Expression in Epstein-Barr Virus Immortalized B Cells and Burkitt Lymphoma Cell Lines of Activated B Cell Phenotype. J Microb Biochem Technol 9:087-094. doi: 10.4172/19485948.1000349

expressed lamin B1, whereas mantle zone lymphocytes were lamin B1 and B2 positive [14]. Cell lines derived from human neoplasms usually mirrored the lamin expression profile of the cell type they derived from [45-48].

Because EBV can alter the epigenotype and gene expression pattern of its target cells, and lamins are epigenetic regulators themselves, we did a systematic analysis of lamin $\mathrm{A} / \mathrm{C}$ expression in EBV-positive and EBV-negative B lymphoid cell lines and analyzed the epigenetic marks of LMNAp $[1,16]$. Unexpectedly, we observed that similarly to the carcinoma cell line of epithelial origin, there was a high level of LMNA transcription in LCLs and in the majority of group III BL lines characterized by an activated B cell phenotype. These cells express typically six nuclear antigens (EBNAs) and three latent membrane proteins (LMPs) encoded by the virus (EBV latency type III) [16]. In contrast, lamin A/C mRNA was present at a low level in EBV-negative $\mathrm{B}$ and $\mathrm{BL}$ lines and in EBV latency type I BL cell lines that expressed only EBNA1.

We noticed that there was a difference in lamin A/C mRNA expression between two clones of the BL line Mutu: Mutu BL-I-Cl-216 (latency I) expressed A-type lamins at a low level, compared to MutuBL-III-Cl-99 (latency III) (Figure 1). Because these clones carry the same EBV strain, one may speculate that one of the EBV-encoded oncoproteins or microRNAs expressed in type III latency may contribute to the activation of LMNAp. Based on microarray data uploaded by Maier et al. [49] (https://www.ncbi.nlm.nih.gov/geoprofiles/24088892) the EBV-encoded nuclear antigen EBNA2 is apparently not involved in LMNAp activation, because expression of EBNA2 in EBV-negative BLs did not result in altered LMNA activity. Similarly to the Mutu clones, Rael cells and CB-M1-Ral-STO cells carry the same EBV strain but differ in latency type and expression of lamin A/C mRNA. In Rael cells (latency type I, EBNA1 only), lamin A/C mRNA was barely detected, whereas it was present in high level in CB-M1-Ral-STO cells expressing six EBNAs and three LMPs (Figure 1). This suggests a role for latent EBV gene products in the regulation of LMNA expression.

A low but variable level of lamin A/C mRNA expression was observed in EBV-negative B (BJAB) and BL cells (DG75; BL41), indicating that cellular factors may also modulate type A lamin expression.

Using bisulfite sequencing, we analyzed the CpG methylation pattern of LMNAp located to a CpG island (Figure 2). A shorter stretch of the very same CpG Island was found to be unmethylated in nodal diffuse large B cell lymphomas actively using the LMNA promoter [45]. The CpG methylation pattern of the LMNA 5 ' regulatory region did not correlate with the activity of the LMNA promoter. Exon 1 was regularly hypermethylated in all BL lines, however, in the vicinity of low-activity LMNA promoters, in contrast to the $\mathrm{B}$ cell lymphoma BJAB, where it was hypomethylated (Figure 2). These data suggested a role for first exon methylation in the down-regulation of LMNA transcription in BL-derived cells. It is interesting to note that Brenet et al. [50] found a linkage between densely methylated first exon sequences and transcriptional silencing in a human acute myelogenous leukemiaderived cell line. Similarly, Yan et al. [51] found that DNA methylation progressively spread from the first exon to the promoter of RASSF1A, a tumor suppressor gene silenced in breast cancer. The LMNA CpG Island may certainly correspond to such a densely methylated first exon in cell lines with low LMNAp activity. In cell lines with highly active $L M N A$ promoters exon 1 was unmethylated or only partially methylated. However, in Mutu-BL-III-Cl-99 and Jijoye p79 that expressed moderate levels of LMNA mRNA, longer or shorter stretches of highly methylated CpGs of exon 1 sequences flanked the promoter (Figure 2). These data indicated that in addition to DNA methylation, other regulatory mechanisms (e.g. histone modifications) also influence LMNAp activity. This notion is supported by the observation that the euchromatic histone marks $\mathrm{AcH} 4$ and $\mathrm{H} 3 \mathrm{~K} 4 \mathrm{me} 2$ were enriched in the 5 ' regulatory region of Mutu-BL-III-Cl-99 cells expressing a high level of lamin A/C mRNA, but not in Mutu BL-I-Cl-216 cells characterized by a low lamin $\mathrm{A} / \mathrm{C}$ mRNA expression. In addition, the 5 ' regulatory sequences and exon 1 of LMNA were marked with the activating histone modifications $\mathrm{AcH} 3, \mathrm{AcH} 4$ and $\mathrm{H} 3 \mathrm{~K} 4 \mathrm{me} 2$ in Jijoye p79 cells expressing a high level of lamin A/C mRNA. We observed that in EBVimmortalized LCLs (latency III) and an NPC cell line the sequences flanking the active LMNA promoter were enriched in euchromatic histone marks (Figure 3). Activating histone marks were absent, however, from low activity LMNA promoters in latency type I BLs. In addition, the histone deacetylase inhibitor TSA could upregulate the activity of LMNAp in two EBV-negative BL lines, whereas the hypomethylating agent 5-azacytidine was ineffective (Figures 4). We observed that TSA treatment was apparently more effective in BJAB cells where the LMNA-associated CpG island was hypomethylated, than in DG75 cells, where the flanking sequences were highly methylated (Figure 4). Thus, in lymphoid cells, both CpG methylation and histone modifications seem to affect LMNAp activity.

In latency type I BL lines and LCLs, there was a clear correlation between the low abundance of euchromatic histone modifications and low level of $L M N A$ transcription. We found, however, that in the EBV-negative B and BL lines BJAB and DG75 enrichment of activating histone modifications at LMNAp was insufficient to achieve a high level of lamin A/C transcripts (Figures 1 and 3). Thus, the presence of euchromatic histone marks at the promoter-flanking sequences could not upregulate $L M N A$ transcription in EBV-negative BL cells, possibly due to the lack of a key viral or cellular activator.

Similarly to LCLs, latency type III BL cells (Mutu-BL-III-Cl-99, Jijoye p79) also expressed relatively high levels of lamin A/C mRNA, with the exception of Raji that does not express, however, the full set of EBV latent proteins: due to deletions in the viral genome, it lacks EBNA3C (EBNA6) and LMP2A [31] (Figure 1). In contrast to the low activity of $L M N A p$ in Raji cells, its flanking sequences were enriched in euchromatic histone modifications (Figures 1 and 3). Further studies may clarify the potential role of EBNA3C (EBNA6) or LMP2A in the regulation of LMNAP.

In addition to genetic events, i.e. mutations, deletions, gene amplifications and chromosomal rearrangements, epigenetic events also contribute both to tumor initiation and tumor progression $[52,53]$. In general, malignant tumors are characterized by global genomic hypomethylation and simultaneous hypermethylation of $\mathrm{CpG}$ islands at tumor suppressor genes [54]. The latter phenomenon can be utilized for the treatment of tumors with epigenetic acting drugs, especially in myelodysplastic syndromes [55]. Moreover, tumor specific hypermethylated DNA sequences (the hypermethylome) appearing in biological fluids may also be exploited for early detection and staging of malignant tumors or may predict the prognosis of the patients [56-58]. Our finding that in EBV negative and EBV latency type I BL lines a low $L M N A$ promoter activity was associated with hypermethylation of the LMNA first exon suggests that the LMNA first exon may belong to a hypermethylome characteristic for BL lines that stably retained the BL biopsy phenotype. It remains to be established, whether demethylation of LMNA first exon and its potential phenotypic consequences could be 
Citation: Banati F, Koroknai A, Szenthe K, Tereh T, Hidasi A, et al. (2017) Up-Regulation of Lamin A/C Expression in Epstein-Barr Virus Immortalized B Cells and Burkitt Lymphoma Cell Lines of Activated B Cell Phenotype. J Microb Biochem Technol 9:087-094. doi: 10.4172/19485948.1000349

exploited in epigenetic therapy of BLs, or whether the hypermethylated first exon of $L M N A$ could be a suitable biomarker for BL.

In cancer cells, $\mathrm{CpG}$ island hypermethylation typically occurs at promoter regions [59]. Our finding suggests that the hypermethylome concept could also be extended to hypermethylated first exon sequences affecting promoter activity.

For the development of EBV-associated lymphomas and carcinomas, epigenetic dysregulation plays an outstanding role, with specific methylation profiles characterizing the different entities posttransplant lymphoproliferative disease, Burkitt lymphoma, Hodgkin lymphoma, nasopharyngeal carcinoma, and gastric carcinoma [60-62]. EBV-induced immortalization of B-cells resembling post-transplant lymphoproliferative disease caused extensive changes in the B-cell methylome affecting $2.18 \mathrm{~GB}$ of the cellular genome and about onethird of all genes [60]. Strikingly, overlapping hypomethylated blocks of 1.7 GB were also observed in the epigenomes of unrelated EBV-negative carcinomas, including colon, lung, breast and thyroid carcinomas and Wilms' tumors [54]. This implies that tumor-specific methylation changes may be used as biomarkers in methylation-specific diagnostic PCR assays from the blood for the early detection of occult tumors [63-65]. Furthermore, hypermethylation at specific tumor suppressor loci may serve as a predictor for the success of chemotherapy $[66,67]$. Epigenetic markers other than methylation, such as expression of repressive PcG proteins and the increased presence of the repressive histone mark H3K27me3 were indicators for a poor prognosis both for NPC, gastric carcinoma and B cell lymphomas [68-71].

\section{Conclusion}

Our data showed that methylation of the first exon of $L M N A$ was associated with the downregulation of LMNA expression whereas euchromatic histone marks were enriched at active $L M N A$ promoters in EBV-immortalized LCLs. These data suggest that viral latency products or their combination may activate LMNAp in EBV infected latency type III B cells in vitro. We speculate that expression of lamin A and lamin $\mathrm{C}$ may contribute to the establishment of activated $\mathrm{B}$ cell phenotype by providing new attachment sites for chromatin loops and thereby affecting the activity of promoters located to lamin-associated domains (LADs) of the genome. Further studies may reveal the contribution of lamin A and C upregulation to the epigenetic reprogramming of LCLs immortalized in vitro and PTLDs, their in vivo counterparts.

\section{References}

1. Berman BP, Weisenberger DJ, Aman JF, Hinoue T, Ramjan Z, et al. (2012) Regions of focal DNA hypermethylation and long-range hypomethylation in colorectal cancer coincide with nuclear lamina-associated domains. Nat Genet 44: $40-46$

2. Guelen L, Pagie L, Brasset E, Meuleman W, Faza MB, et al. (2008) Domain organization of human chromosomes revealed by mapping of nuclear lamina interactions. Nature 453: 948-951

3. Hutchison CJ, Worman HJ (2004) A-type lamins: Guardians of the soma? Nat Cell Biol 6: 1062-1067.

4. Kind J, Pagie L, Ortabozkoyun H, Boyle S, de Vries SS, et al. (2013) Single-cell dynamics of genome-nuclear lamina interactions. Cell 153: 178-192.

5. Pickersgill H, Kalverda B, de Wit E, Talhout W, Fornerod M, et al. (2006) Characterization of the Drosophila melanogaster genome at the nuclear lamina. Nat Genet 38: 1005-1014

6. Towbin BD, Gonzalez-Sandoval A, Gasser SM (2013) Mechanisms of heterochromatin subnuclear localization. Trends Biochem Sci 38: 356-363.

7. Van Bemmel JG, Pagie L, Braunschweig U, Brugman W, Meuleman W, et al. (2010) The insulator protein SU(HW) fine-tunes nuclear lamina interactions of the Drosophila genome. PLoS ONE 5: e15013.
8. Taddei A, Hediger F, Neumann FR, Gasser SM (2004) The function of nuclear architecture: A genetic approach. Annu Rev Genet 38: 305-345.

9. Ho CY, Lammerding J (2012) Lamins at a glance. J Cell Sci 125: 2087-2093.

10. Eckersley-Maslin MA, Bergmann JH, Lazar Z, Spector DL (2013) Lamin A/C is expressed in pluripotent mouse embryonic stem cells. Nucleus 4: 53-60.

11. Prokocimer M, Davidovich M, Nissim-Rafinia M, Wiesel-Motiuk N, Bar DZ, et al. (2009) Nuclear lamins: Key regulators of nuclear structure and activities. J Cell Mol Med 13: 1059-1085.

12. Rober RA, Weber K, Osborn M (1989) Differential timing of nuclear lamin a/c expression in the various organs of the mouse embryo and the young animal: $A$ developmental study. Development 105: 365-378.

13. Guilly MN, Kolb JP, Gosti F, Godeau F, Courvalin JC (1990) Lamins A and C are not expressed at early stages of human lymphocyte differentiation. Exp Cell Res 189: 145-147.

14. Jansen MP, Machiels BM, Hopman AH, Broers JL, Bot FJ, et al. (1997) Comparison of a and b-type lamin expression in reactive lymph nodes and nodular sclerosing Hodgkin's disease. Histopathology 31: 304-312.

15. Rober RA, Sauter H, Weber K, Osborn M (1990) Cells of the cellular immune and hemopoietic system of the mouse lack lamins a/c: Distinction versus other somatic cells. J Cell Sci 95: 587-598.

16. Takacs M, Banati F, Koroknai A, Segesdi J, Salamon D, et al. (2010) Epigenetic regulation of latent Epstein-Barr virus promoters. Biochim Biophys Acta 1799: 228-235.

17. Niller HH, Banati F, Ay E, Minarovits J (2012) Epigenetic changes in virusassociated neoplasms. In Patho-epigenetics of disease. Minarovits $\mathrm{J}$, Niller $\mathrm{HH}$, Eds. Springer Science+Business Media: New York, pp: 179-225.

18. Hu LF, Chen F, Zhen QF, Zhang YW, Luo Y, et al. (1995) Differences in the growth pattern and clinical course of ebv-Imp1 expressing and non-expressing nasopharyngeal carcinomas. Eur J Cancer 31A: 658-660.

19. Cai X, Schäfer A, Lu S, Bilello JP, Desrosiers RC, et al. (2006) Epstein-Barr virus microRNAs are evolutionarily conserved and differentially expressed. PLoS Pathog 2: e23.

20. Gratama JW, Zutter MM, Minarovits J, Oosterveer MA, Thomas ED, et al. (1991) Expression of epstein-barr virus-encoded growth-transformation-associated proteins in lymphoproliferations of bone-marrow transplant recipients. Int $J$ Cancer 47: 188-192.

21. Carter KL, Cahir-McFarland E, Kieff E (2002) Epstein-Barr virus-induced changes in B-lymphocyte gene expression. J Virol 76: 10427-10436.

22. Niller HH, Wolf H, Minarovits J (2009) Epigenetic dysregulation of the host cell genome in Epstein-Barr virus-associated neoplasia. Semin Cancer Biol 19 158-164.

23. Bose S, Yap LF, Fung M, Starzcynski J, Saleh A, et al. (2009) The ATM tumou suppressor gene is down-regulated in EBV-associated nasopharyngeal carcinoma. J Pathol 217: 345-352.

24. An FQ, Compitello N, Horwitz E, Sramkoski M, Knudsen ES, et al. (2005) The latency-associated nuclear antigen of Kaposi's sarcoma-associated herpes virus modulates cellular gene expression and protects lymphoid cells from $\mathrm{p} 16$ ink4a-induced cell cycle arrest. J Biol Chem 280: 3862-3874.

25. Szenthe K, Koroknai A, Banati F, Bathori Z, Lozsa R, et al. (2013) The 5 regulatory sequences of active mir-146a promoters are hypomethylated and associated with euchromatic histone modification marks in b lymphoid cells. Biochem Biophys Res Commun 433: 489-495.

26. [No authors listed] (2000) UKCCCR guidelines for the use of cell lines in cancer research. Br J Cancer 82: 1495-1509.

27. Wennborg A, Aman P, Saranath D, Pear W, Sumegi J, et al. (1987) Conversion of the lymphoma line "bjab" by Epstein-Barr virus into phenotypically altered sublines is accompanied by increased c-myc mrna levels. Int J Cancer 40: 202-206.

28. Ernberg I, Falk K, Minarovits J, Busson P, Tursz T, et al. (1989) The role of methylation in the phenotype-dependent modulation of Epstein-Barr nuclear antigen 2 and latent membrane protein genes in cells latently infected with Epstein-Barr virus. J Gen Virol 70: 2989-3002.

29. Gregory CD, Rowe M, Rickinson AB (1990) Different Epstein-Barr virus-B cell interactions in phenotypically distinct clones of a Burkitt's lymphoma cell line. J Gen Virol 71: 1481-1495. 
Citation: Banati F, Koroknai A, Szenthe K, Tereh T, Hidasi A, et al. (2017) Up-Regulation of Lamin A/C Expression in Epstein-Barr Virus Immortalized B Cells and Burkitt Lymphoma Cell Lines of Activated B Cell Phenotype. J Microb Biochem Technol 9:087-094. doi: 10.4172/19485948.1000349

30. Masucci MG, Torsteindottir S, Colombani J, Brautbar C, Klein E, et al. (1987) Down-regulation of class i hla antigens and of the Epstein-Barr virus-encoded latent membrane protein in Burkitt lymphoma lines. Proc Natl Acad Sci U S A 84: 4567-4571

31. Hatfull G, Bankier AT, Barrell BG, Farrell PJ (1988) Sequence analysis of Raj Epstein-Barr virus DNA. Virology 164: 334-340

32. Kavathas P, Bach FH, DeMars R (1980) Gamma ray-induced loss of expression of HLA and glyoxalase I alleles in lymphoblastoid cells. Proc Natl Acad Sci U S A 77: 4251-4255.

33. Bakos A, Banati F, Koroknai A, Takacs M, Salamon D, et al. (2007) Highresolution analysis of CpG methylation and in vivo protein-DNA interactions at the alternative Epstein-Barr virus latency promoters $\mathrm{Qp}$ and $\mathrm{Cp}$ in the nasopharyngeal carcinoma cell line C666-1. Virus Genes 35: 195-202.

34. Cheung ST, Huang DP, Hui AB, Lo KW, Ko CW, et al. (1999) Nasopharyngea carcinoma cell line (c666-1) consistently harbouring Epstein-Barr virus. Int $J$ Cancer 83: 121-126.

35. Gerle B, Koroknai A, Fejer G, Bakos A, Banati F, et al. (2007) Acetylated histone $\mathrm{H} 3$ and $\mathrm{H} 4$ mark the upregulated LMP2A promoter of Epstein-Barr virus in lymphoid cells. J Virol 81: 13242-13247.

36. Frommer M, McDonald LE, Millar DS, Collis CM, Watt F, et al. (1992) A genomic sequencing protocol that yields a positive display of 5-methylcytosine residues in individual DNA strands. Proc Natl Acad Sci U S A 89: 1827-1831.

37. Myohanen S, Wahlfors J, Janne J (1994) Automated fluorescent genomic sequencing as applied to the methylation analysis of the human ornithine decarboxylase gene. DNA Seq 5: 1-8

38. Weinmann AS, Farnham PJ (2002) Identification of unknown target genes of human transcription factors using chromatin immunoprecipitation. Methods 26 : $37-47$

39. Fejer G, Koroknai A, Banati F, Gyory I, Salamon D, et al. (2008) Latency typespecific distribution of epigenetic marks at the alternative promoters $\mathrm{cp}$ and $\mathrm{qp}$ of epstein-barr virus. J Gen Virol 89: 1364-1370.

40. Sjöblom-Hallén A, Yang W, Jansson A, Rymo L (1999) Silencing of the EpsteinBarr virus latent membrane protein 1 gene by the Max-Mad1-mSin3A modulator of chromatin structure. J Virol 73: 2983-2993.

41. Burke B, Stewart CL (2013) The nuclear lamins: Flexibility in function. Nat Rev Mol Cell Biol 14: 13-24

42. Simon DN, Wilson KL (2013) Partners and post-translational modifications of nuclear lamins. Chromosoma 122: 13-31.

43. Broers JL, Machiels BM, Kuijpers HJ, Smedts F, van den Kieboom R, et al. (1997) A- and B-type lamins are differentially expressed in normal human tissues. Histochem Cell Biol 107: 505-517.

44. Lin F, Worman HJ (1997) Expression of nuclear lamins in human tissues and cancer cell lines and transcription from the promoters of the lamin $A / C$ and $B 1$ genes. Exp Cell Res 236: 378-384.

45. Agrelo R, Setien F, Espada J, Artiga MJ, Rodriguez M, et al. (2005) Inactivation of the lamin a/c gene by CpG island promoter hypermethylation in hematologic malignancies and its association with poor survival in nodal diffuse large B-cell lymphoma. J Clin Oncol 23: 3940-3947.

46. Guilly MN, Bensussan A, Bourge JF, Bornens M, Courvalin JC (1987) A human T lymphoblastic cell line lacks lamins A and C. EMBO J 6: 3795-3799.

47. Pollard KM, Chan EK, Grant BJ, Sullivan KF, Tan EM, et al. (1990) In vitro posttranslational modification of lamin B cloned from a human T-cell line. Mol Cell Biol 10: 2164-2175

48. Stadelmann B, Khandjian E, Hirt A, Luthy A, Weil R, et al. (1990) Repression of nuclear lamin a and $c$ gene expression in human acute lymphoblastic leukemia and non-Hodgkin's lymphoma cells. Leuk Res 14: 815-821.

49. Maier S, Staffler G, Hartmann A, Höck J, Henning K, et al. (2006) Cellular targe genes of Epstein-Barr virus nuclear antigen 2. J Virol 80: 9761-9771.

50. Brenet F, Moh M, Funk P, Feierstein E, Viale AJ, et al. (2011) DNA methylation of the first exon is tightly linked to transcriptional silencing. PLOS ONE 6: e14524.

51. Yan PS, Shi H, Rahmatpanah F, Hsiau TH, Hsiau AH, et al. (2003) Differentia distribution of DNA methylation within the rassf1a $\mathrm{CpG}$ Island in breast cancer. Cancer Res 63: 6178-6186.
52. Jones PA, Baylin SB (2007) The epigenomics of cancer. Cell 128: 683-692.

53. Muñoz P, Iliou MS, Esteller M (2012) Epigenetic alterations involved in cancer stem cell reprogramming. Mol Oncol 6: 620-636

54. Hansen KD, Timp W, Bravo HC, Sabunciyan S, Langmead B, et al. (2011) Increased methylation variation in epigenetic domains across cancer types. Nat Genet 43: 768-775.

55. Claus R, Almstedt M, Lübbert M (2005) Epigenetic treatment of hematopoietic malignancies: In vivo targets of demethylating agents. Semin Oncol 32: 511-

56. Schuebel KE, Chen W, Cope L, Glockner SC, Suzuki H, et al. (2007) Comparing the DNA hypermethylome with gene mutations in human colorectal cancer PLoS Genet 3: 1709-1723.

57. Esteller M (2007) Epigenetic gene silencing in cancer: The DNA hypermethylome. Hum Mol Genet 16 Spec No 1: R50-59.

58. Jeschke J, Van Neste L, Glockner SC, Dhir M, Calmon MF, et al. (2012) Biomarkers for detection and prognosis of breast cancer identified by a functional hypermethylome screen. Epigenetics 7: 701-709.

59. Esteller M (2002) CpG island hypermethylation and tumor suppressor genes: A booming present, a brighter future. Oncogene 21: 5427-5440.

60. Hansen KD, Sabunciyan S, Langmead B, Nagy N, Curley R, et al. (2014) Large-scale hypomethylated blocks associated with Epstein-Barr virus-induced b-cell immortalization. Genome Res 24: 177-184.

61. Niller HH, Banati F, Minarovits J (2014) Epigenetic alterations in nasopharyngea carcinoma and Epstein-Barr virus (EBV) associated gastric carcinoma: A lesson in contrasts. Journal of Nasopharyngeal Carcinoma 1.

62. Niller HH, Banati F, Salamon D, Minarovits J (2016) Epigenetic alterations in Epstein-Barr virus-associated diseases. Adv Exp Med Biol 879: 39-69.

63. Li J, Gong P, Lyu X, Yao K, Li X, et al. (2014) Aberrant CpG island methylation of PTEN is an early event in nasopharyngeal carcinoma and a potential diagnostic biomarker. Oncol Rep 31: 2206-2212.

64. Hutajulu SH, Indrasari SR, Indrawati LP, Harijadi A, Duin S, et al. (2011) Epigenetic markers for early detection of nasopharyngeal carcinoma in a high risk population. Mol Cancer 10: 48.

65. Zhang Z, Sun D, Hutajulu SH, Nawaz I, Nguyen Van, et al. (2012) Developmen of a non-invasive method, multiplex methylation specific PCR (MMSP), for early diagnosis of nasopharyngeal carcinoma. PLoS ONE 7: e45908.

66. Seo SY, Kim EO, Jang KL (2008) Epstein-barr virus latent membrane protein 1 suppresses the growth-inhibitory effect of retinoic acid by inhibiting retinoic acid receptor-beta2 expression via DNA methylation. Cancer Lett 270: 66-76.

67. Zhang X, Li W, Li H, Ma Y, He G, et al. (2012) Genomic methylation profiling combined with gene expression microarray reveals the aberrant methylation mechanism involved in nasopharyngeal carcinoma taxol resistance. Anticance Drugs 2012, 23, 856-864.

68. Cai MY, Tong ZT, Zhu W, Wen ZZ, Rao HL, et al. (2011) H3k27me3 protein is a promising predictive biomarker of patients' survival and chemoradio resistance in human nasopharyngeal carcinoma. Mol Med 17: 1137-1145.

69. Hwang CF Huang HY, Chen CH, Chien CY, Hsu YC, et al. (2012) Enhancer of zeste homolog 2 overexpression in nasopharyngeal carcinoma: An independen poor prognosticator that enhances cell growth. Int J Radiat Oncol Biol Phys 82 : 597-604

70. He LJ, Cai MY, Xu GL, Li JJ, Weng ZJ, et al. (2012) Prognostic significance of overexpression of ezh2 and h3k27me3 proteins in gastric cancer. Asian Pac J Cancer Prev 13: 3173-3178.

71. Van Kemenade FJ, Raaphorst FM, Blokzijl T, Fieret E, Hamer KM, et al. (2001) Co-expression of bmi-1 and ezh2 polycomb-group proteins is associated with cycling cells and degree of malignancy in B-cell non-Hodgkin lymphoma. Blood 97: 3896-3901

Citation: Banati F, Koroknai A, Szenthe K, Tereh T, Hidasi A, et al. (2017) Up-Regulation of Lamin A/C Expression in Epstein-Barr Virus Immortalized Cells and Burkitt Lymphoma Cell Lines of Activated B Cell Phenotype. J Microb Biochem Technol 9:087-094. doi: 10.4172/1948-5948.1000349 